\title{
EQ-5D-Y-5L: developing a revised EQ-5D-Y with increased response categories
}

\author{
Simone Kreimeier ${ }^{1}$ Mimmi Åström ${ }^{2,3,4} \cdot$ Kristina Burström $^{2,3,4} \cdot$ Ann-Charlotte Egmar $^{2,5} \cdot$ Narcis Gusi $^{6}$. \\ Michael Herdman ${ }^{7} \cdot$ Paul Kind $^{8,9} \cdot$ Miguel A. Perez-Sousa $^{6} \cdot$ Wolfgang Greiner $^{1}$
}

Accepted: 14 January 2019 / Published online: 9 February 2019

(c) The Author(s) 2019

\begin{abstract}
Purpose EQ-5D-Y is a generic measure of health status for children and adolescents aged 8-15 years. Originally, it has three levels of severity in each dimension (3L). This study aimed to develop a descriptive system of EQ-5D-Y with an increased number of severity levels and to test comprehensibility and feasibility.

Methods The study was conducted in Germany, Spain, Sweden and the UK. In Phase 1, a review of existing instruments and focus group interviews were carried out to create a pool of possible labels for a modified severity classification. Participants aged 8-15 rated the severity of the identified labels in individual sorting and response scaling interviews. In Phase 2, preliminary $4 \mathrm{~L}$ and $5 \mathrm{~L}$ versions were constructed for further testing in cognitive interviews with healthy participants aged $8-15$ years and children receiving treatment for a health condition.

Results In Phase 1, a total of 233 labels was generated, ranging from 37 (UK) to 79 labels (Germany). Out of these, 7 to 16 possible labels for each dimension in the different languages were rated in 255 sorting and response scaling interviews. Labels covered an appropriate range of severity on the health continuum in all countries. In Phase 2, the 5L version was generally preferred (by $68-88 \%$ of the participants per country) over the $4 \mathrm{~L}$ version.

Conclusions This multinational study has provided a version of the EQ-5D-Y with 5 severity levels in each dimension. This extended version (EQ-5D-Y-5L) requires testing its psychometric properties and its performance compared to that of the original EQ-5D-Y-3L.
\end{abstract}

Keywords EQ-5D-Y $\cdot$ EQ-5D-Y-3L $\cdot$ EQ-5D-Y-5L $\cdot$ Health-related quality of life $(H R Q o L) \cdot$ Children $\cdot$ Adolescent

Electronic supplementary material The online version of this article (https://doi.org/10.1007/s11136-019-02115-x) contains supplementary material, which is available to authorized users.

Simone Kreimeier

simone.kreimeier@uni-bielefeld.de

1 Department of Health Economics and Health Care Management, School of Public Health, Bielefeld University, Universitätsstraße 25, 33615 Bielefeld, Germany

2 Health Outcomes and Economic Evaluation Research Group, Stockholm Centre for Healthcare Ethics, Department of Learning, Informatics, Management and Ethics, Karolinska Institutet, 17177 Stockholm, Sweden

3 Equity and Health Policy Research Group, Department of Public Health Sciences, Karolinska Institutet, 17177 Stockholm, Sweden

4 Health Care Services, Stockholm County Council, 17177 Stockholm, Sweden
5 Department of Public Health and Medicine, Health-Promotion Interventions and Resilience, The Swedish Red Cross University College, 14157 Huddinge, Sweden

6 Faculty of Sport Sciences, University of Extremadura, Badajoz, Spain

7 Office of Health Economics, London, UK

8 Academic Unit of Health Economics, Leeds Institute of Health Sciences, University of Leeds, Leeds, UK

9 Centre for Health Economics, Management and Policy, Higher School of Economics, St Petersburg, Russia 


\section{Introduction}

Since 2010, the EQ-5D-Y has been available as a 'Youth' version of the EQ-5D, for children and adolescents aged 8-15 years. The instrument was developed using the standard three-level (3L) format of the EQ-5D descriptive system (adult version). Like the EQ-5D, the current EQ-5D-Y-3L descriptive system comprises five dimensions of health; 'mobility', 'looking after myself', 'doing usual activities', 'having pain or discomfort', 'feeling worried, sad or unhappy'. Each dimension has three levels of severity, resulting in a total of 243 possible health states. Although the same dimension and response option structure as used in the EQ-5D-3L was retained, the wording and layout were modified to be suitable for children and adolescents [1-3]. The EQ-5D-Y-3L has demonstrated its feasibility in children and adolescents with different health conditions [4-6].

In 2011, the EQ-5D-5L, a five-level (5L) version of the EQ-5D for adults, was introduced, with the aim of reducing the instrument's ceiling effects and enhancing sensitivity, especially in milder health conditions [7]. Testing of the $5 \mathrm{~L}$ adult version has shown that it works as well or better than the $3 \mathrm{~L}$ in various conditions and settings [8-10].

As with the $3 \mathrm{~L}$ adult version, there is evidence of ceiling effects for the EQ-5D-Y-3L and it has been criticized for being overly simplistic and potentially insensitive to small changes in health status $[6,11,12]$. In contrast to the EQ-5D-Y-3L, the majority of generic health-related quality of life (HRQoL) instruments for children and adolescents, such as the KINDL or PedQL $[13,14]$, use response options with more than three levels of severity. Expanding the number of severity levels in each dimension of the EQ-5D-Y might help to reduce ceiling effects and improve sensitivity.

The aim of the present study was to develop a descriptive system of the EQ-5D-Y with an increased number of severity levels and to test the comprehensibility and feasibility of the extended version. The number of levels in the final version was not defined a priori as a further aim of the study was to assess children's opinion and the acceptability of using versions with 4 or 5 levels of severity in each dimension.

\section{Methods}

This study was conducted in Germany, Spain, Sweden and the UK between May 2014 and June 2018. Ethical approval was obtained in each country. The study had two phases. In phase 1, potential severity labels were identified, sorting and response scaling interviews were conducted, and alternative $4 \mathrm{~L}$ and $5 \mathrm{~L}$ versions of EQ-5D-Y were developed for each country. In phase 2 , both versions were tested for comprehensibility and feasibility and children's opinion about the two versions were elicited. In both phases, a common standardized protocol was used to ensure that the same procedures were followed in each country.

\section{Phase 1}

\section{Identifying a pool of labels for the severity levels}

Procedure A pool of possible labels for the extension of EQ-5D-Y-3L severity levels was developed from a review of HRQoL instruments and by focus group interviews. Existing generic as well as disease-specific HRQoL instruments for children in the four different languages were included with the aim of identifying labels which covered the full range of severity. Dictionaries and thesauruses were used to search for synonyms of previously identified labels. When deciding which labels to include in the final pool, the lexical structure of the EQ-5D-Y was taken into account. Only labels describing the 'quantity' or 'intensity' of health problems (e.g., a lot of, slight) were included and, e.g., terms relating to frequencies, were excluded.

In addition, each country conducted two focus group interviews, one with children aged 8-10 and one with participants aged 11-15, as it was assumed that younger children would be more willing to participate and less shy in a separate group. Children without any obvious health problems were drawn from the general population through collaboration with local schools and sports clubs. To participate, the relevant local language had to be the main one spoken in the participant's home.

The aim of the focus group interviews was to identify child-friendly labels normally used by the target group. In general, focus group interviews have predominantly been conducted with adults [15]. However, there is evidence that these are feasible with younger participants for use in the development of child-specific HRQoL instruments to gather information about the wording and vocabulary of children and adolescents themselves $[15,16]$.

Children and adolescents were first asked to talk about their own experiences with illness before being asked to describe pictures illustrating people with a health condition. This procedure aimed to identify words and phrases that children and adolescents used naturally and spontaneously when talking about health and illness. We were particularly interested in words young people used to describe the quantity or intensity of health problems. Subsequently, children were asked to rank the labels elicited from the earlier review of instruments between no problems to the most 
Table 1 Definition of approximated mean values of the labels used for the two extended versions of the EQ-5D-Y

\begin{tabular}{llll}
\hline Version & Age group (years) & $\begin{array}{l}\text { Development of targeted distances } \\
\text { between labels }\end{array}$ & $\begin{array}{l}\text { Approximated mean } \\
\text { values and distances }\end{array}$ \\
\hline $4 \mathrm{~L}$ & $8-10$ & 5 smilies; 4 labels needed & $1.25-2.5-3.75-5$ \\
& $11-15$ & VAS from 0 to 10; 4 labels needed & $0-3.4-6.8-10$ \\
$5 \mathrm{~L}$ & $8-10$ & 5 smilies; 5 labels needed & $1-2-3-4-5$ \\
& $11-15$ & VAS from 0 to $10 ; 5$ labels needed & $0-2.5-5-7.5-10$ \\
\hline
\end{tabular}

severe problems they could imagine. Lastly, the participants indicated the labels that they did not like or understand as well as those they liked the most.

Data analysis The focus group discussions were documented by detailed notes or recorded and transcribed and then analyzed using thematic content analysis [17]. As typical for this kind of analysis, we defined categories (e.g., 'labels mentioned by the participants themselves', 'information about the labels in the context of the ranking') and screened the participants' comments for statements referring to these categories. Based on the results from the review and the focus groups, each country identified a pool of potential labels for use with each dimension of the EQ-5D-Y.

\section{Sorting and response scaling interviews}

Procedure Sorting and response scaling techniques were used in individual interviews with children and adolescents to determine the relative severity of each label identified in phase I. Sorting tasks were used with younger children (8-10 years) while older children (11-15 years) completed response scaling tasks.

A convenience sample of children and adolescents aged 8-15 years from the general population of school children recruited in primary and secondary schools was used. Different types of schools were included to ensure the participation of children and adolescents with different educational levels and socio-economic background. A total of 60 participants in each country was expected with 20 in each age group: 8-10 years, 11-2 years and 13-15 years. The sample size was somewhat larger than that used in developing the adult version EQ-5D-5L [7], as the surveyed population of children and adolescents was considered to be more heterogeneous in terms of age and verbal comprehension.

In the context of the development of HRQoL instruments, the response scaling method typically requires participants to assign a numeric rating to an item or label. This method has already been used in the development of other HRQoL instruments [18, 19]. In this study, older respondents (11-15 years) were asked to rate the severity of each label separately on a visual analog scale (VAS) from 0 to 10 (detailed labeling of the anchors see legend of Table 4). For younger children (8-10 years), the different categories of severity were presented on a 'smiling face' scale. Smiley faces are often used for child-friendly measures [20, 21]. We used a modified version of the faces scale from the UK Household Longitudinal Study [22]. For each label, the younger children were asked to choose one smiley out of five smileys (from $1=$ smiley of very bad mood to $5=$ smiley of very good mood). The anchors of the scale, so smiley 1 and smiley 5 , were labelled in the same way as done for the anchors of the VAS that was used for the older participants.

All children rated all labels separately for each dimension. Participants were asked to indicate labels that they found hard to understand or which they did not use in daily language. Both the order in which dimensions and labels were presented to the participants were randomized to avoid bias. A pilot test of the tasks was conducted before being applied to the full sample.

Data analysis Labels were first grouped into two categories ('unusual and unclear labels'; 'usual and easily understood labels') based on participants' comments. Mean (standard deviation), median, mode, minimum and maximum of the sorting and response scaling data were then computed for all labels using SPSS version 23. These analyses were done separately for younger and older participants as the scale for the younger participants ranged from 1 to 5 while it was 0 to 10 for the older participants.

Criteria for label selection Labels were selected for further testing based primarily on their distribution along the severity continuum. As both 4L and 5L formats were being considered, two sets of criteria were specified as shown in Table 1.

Labels were considered appropriate for the extended versions, if the following criteria were met (ordered from most to least importance): (1) median and mode showed exactly the previously defined values (Table 1 ) or they were close to it, (2) median and mode had the same value, (3) standard deviation was very small, as that would show similarity of interpretation among respondents. The labels for the upper ('unable to', 'extreme pain or discomfort', 'extremely worried, sad or unhappy') and lower ( 'no problems', 'no pain or discomfort', 'not worried, sad or unhappy') levels of severity were selected as used for the anchors in the sorting and 
response scaling tasks as these showed good comprehensibility and feasibility.

If there were uncertainties about the final decision for a label and more than one label was appropriate for a severity level based on the quantitative results, the results of the qualitative data analysis were taken into account when making the final decision. At the end of this phase, draft $4 \mathrm{~L}$ and $5 \mathrm{~L}$ versions were available.

\section{Phase 2}

\section{Cognitive interviews}

Procedure Cognitive interviews were conducted to test the $4 \mathrm{~L}$ and $5 \mathrm{~L}$ draft versions for comprehensibility, feasibility and preferences between versions. In Germany, Spain and Sweden, healthy children and adolescents aged 8-15 years as well as those in treatment for a health condition participated in individual or group interviews. Healthy participants were recruited in collaboration with schools and participants with a health condition in collaboration with local hospitals. The interviews took place in a separate room assigned by the schools or hospitals. Participants with a health condition were included to get feedback from children who might use labels representing higher levels of severity.

According to the standardized protocol, participants first completed either the $4 \mathrm{~L}$ or $5 \mathrm{~L}$ to record their own health status, followed by a general discussion of the version. Participants then completed socio-demographic questions, before completing the other draft version and discussing that. Finally, they were asked which version they preferred and why. To avoid an ordering bias, the order of versions was varied. When discussing the versions, the paraphrasing method was used, whereby participants were asked to rephrase the items in their own words; probing was used to explore problems in answering, comprehension, and participants' reasons for choosing a given response option [23].

In the UK, a slightly different approach was taken. Two focus group interviews were conducted to test the provisional 5L version. Pupils from primary and secondary schools participated. Recruitment of children with current experience of illness would have necessitated obtaining separate ethical approval from the National Health Service (NHS). This would have incurred significant delay so that recruitment was limited to children attending schools. Participants were initially asked to record their current health status using the $5 \mathrm{~L}$ version and then to review the first page and to circle any words or phrases that might be difficult to understand for other people of their age. These words were discussed in the group. In addition, the participants reported how hard or easy they found it to answer the version. Finally, each pupil was asked to complete a written task designed to
Table 2 Number of severity labels selected for sorting and response scaling per dimension, by country

\begin{tabular}{lllll}
\hline Dimension & \multicolumn{3}{l}{ Countries } & \\
\cline { 2 - 5 } & Germany & Spain & Sweden & UK \\
\hline Mobility & 15 & 13 & 13 & 8 \\
Looking after myself & 15 & 13 & 13 & 8 \\
Doing usual activities & 15 & 13 & 13 & 8 \\
Having pain or discomfort & 16 & 11 & 12 & 7 \\
Feeling worried sad or unhappy & 12 & 12 & 11 & 7 \\
\hline
\end{tabular}

test their comprehension of key words and phrases that were considered to be the most problematic.

Data analysis The interviews and group discussions were recorded, transcribed and analyzed using thematic content analysis [17]. Comments made by participants were assigned to defined categories such as 'general comprehensibility and ease of use', 'comprehensibility of labels', and 'suggestions for changes'.

\section{Harmonization}

As we wanted to develop language-specific versions from scratch, we did not expect to find absolute equivalent labels in all countries. However, the three 5L language versions (Swedish, Spanish, German) were translated into English and compared to each other and to the UK English version. Any discrepancies between versions were discussed in a harmonization exercise involving researchers from each country.

\section{Results}

\section{Phase 1}

\section{Identifying a pool of possible labels for the severity levels}

The review of HRQoL instruments and focus groups identified potentially usable labels (Germany: 79; Spain: 67; Sweden: 50; UK: 37) from which a smaller number of labels per dimension was selected for inclusion in the sorting and response scaling interviews (Table 2). During the screening of HRQoL instruments to select some candidate labels, the UK team was quite strict with regard to whether the labels were grammatically well compatible with the general format of EQ-5D dimension statements and whether they seemed to be child-friendly. This led to a smaller initial label pool than in other countries. The German label pool was quite big due to a complicated language that offered several options of wording. The German 
Table 3 Sample description for the sorting and response scaling interviews, by country

\begin{tabular}{lllll}
\hline & Germany & Spain & Sweden & UK \\
& 64 & 72 & 60 & 58 \\
& $\%(n)$ & $\%(n)$ & $\%(n)$ & $\%(n)$ \\
\hline Gender & & & & \\
Boys & $43.8(28)$ & $50.0(36)$ & $38.3(23)$ & $46.6(27)$ \\
Girls & $56.3(36)$ & $50.0(36)$ & $61.7(37)$ & $53.4(31)$ \\
Age-groups(years) & & & & \\
$8-10$ & $32.8(21)$ & $43.1(31)$ & $41.7(25)$ & $50.8(30)$ \\
$11-15$ & $67.2(43)$ & $56.9(41)$ & $58.3(35)$ & $49.2(28)$ \\
Chronic/long-lasting & illness & & & \\
Yes & $29.7(19)$ & $22.2(16)$ & $35.0(21)$ & - \\
No & $70.3(45)$ & $77.7(56)$ & $61.7(39)$ & - \\
Don't know & - & $2.7(2)$ & $3.3(2)$ & - \\
EQ-VAS (median) & 90.0 & 95.0 & 86.0 & 88.0 \\
\hline
\end{tabular}

${ }^{\text {a }}$ Dividing the age-groups like this is based on the split of age ranges in the field work in phase 1 and 2

team wanted to give the chance to children and adolescents to give their view on many different labels. Labels representing the full range of severity were included in all countries. The same set of labels was applied for the 'mobility', 'looking after myself' and 'usual activities' dimensions and a somewhat different set for the 'having pain or discomfort' and 'feeling worried, sad or unhappy' dimensions.

\section{Sorting and response scaling interviews}

Each country conducted between 59 and 72 sorting and response scaling interviews giving a total of 255 interviews. Detailed information about the sample characteristics are shown in Table 3.

Table 4 shows the range of median values for the 'mobility' dimension based on the responses of the participants aged 11-15 years, while Table 5 provides the same information for the 'feeling worried, sad and unhappy' dimension. These are provided as examples as the range of values for the other dimensions was similar. Labels covered an appropriate range of severity on the health continuum in all countries. The ratings from the participants aged $8-10$ years were comparable to those from the older participants.

Median values, mode and standard deviation were considered in the decision regarding final labels for the $4 \mathrm{~L}$ and $5 \mathrm{~L}$ versions, as well as participants' verbal statements. For example, the Swedish labels 'pyttelite' (a tiny bit) and 'något' (some, somewhat) for dimensions 'mobility', 'looking after myself' and 'doing usual activities' were ranked differently among the two age groups, who also appeared to interpret the words in different ways. Hence, these words were not chosen as final labels. The importance of the verbal

Table 4 Median VAS for the labels rated for the 'mobility' dimension in the response scaling interviews by participants aged 11-15 years, by country

\begin{tabular}{|c|c|c|c|c|c|c|c|}
\hline \multicolumn{2}{|l|}{ Germany } & \multicolumn{2}{|l|}{ Spain } & \multicolumn{2}{|l|}{ Sweden } & \multicolumn{2}{|l|}{ UK } \\
\hline $\begin{array}{l}\text { Labels 'mobil- } \\
\text { ity' dimension }\end{array}$ & Median value $^{\mathrm{a}}$ & $\begin{array}{l}\text { Labels 'mobil- } \\
\text { ity' dimension }\end{array}$ & Median value $^{b}$ & $\begin{array}{l}\text { Labels 'mobil- } \\
\text { ity' dimension }\end{array}$ & Median value* & $\begin{array}{l}\text { Labels 'mobil- } \\
\text { ity' dimension }\end{array}$ & Median value \\
\hline Keine & 0 & No & 0 & Inte & 0 & No & 100 \\
\hline Kaum & 0.9 & Casi no & 5 & Pyttelite & 1 & A little bit & 80 \\
\hline Ganz leichte & 1 & Escasos & 20 & Bara lite & 2 & A bit & 70 \\
\hline Wenige & 2 & Un poco & 30 & Lite & 2 & Some & 55 \\
\hline Leichte & 2 & Algunos & 42 & Lite grann & 2 & A lot & 30 \\
\hline Ein wenig & 2 & Moderados & 50 & En aning & 2.5 & A great deal & 20 \\
\hline Ein bisschen & 2 & Bastantes & 65 & Något & 3 & Terrible & 10 \\
\hline Ein paar & 3 & Muchos & 70 & Ganska & 6 & Cannot & 0 \\
\hline Einige & 5 & Muchisimos & 75 & Mycket & 8 & - & - \\
\hline Viele & 7.5 & Severos & 80 & Väldigt & 8 & - & - \\
\hline Große & 8 & Graves & 85 & Jätte & 9 & - & - \\
\hline Sehr viele & 8.5 & Extremos & 90 & Extremt & 9.5 & - & - \\
\hline Sehr große & 9 & No puedo & 100 & Kan inte & 10 & - & - \\
\hline Extreme & 9.8 & - & - & - & - & - & - \\
\hline Kann nicht & 10 & - & - & - & - & - & - \\
\hline
\end{tabular}

a'VAS from 0 to 10 was used. Anchor ' 0 ' was labelled as 'no' and anchor '10' was labelled as 'cannot'

bVAS from 0 to 100 was used. Anchor ' 0 ' indicated the best status and anchor ' 100 ' indicated the worst status

'VAS from 0 to 100 was used. Anchor ' 0 ' was labelled as 'cannot' and anchor '100' was labelled as 'no' 
Table 5 Median VAS for the labels rated for the 'feeling worried, sad or unhappy' dimension in the response scaling interviews by participants aged $11-15$ years, by country

\begin{tabular}{|c|c|c|c|c|c|c|c|}
\hline \multicolumn{2}{|l|}{ Germany } & \multicolumn{2}{|l|}{ Spain } & \multicolumn{2}{|l|}{ Sweden } & \multicolumn{2}{|l|}{ UK } \\
\hline $\begin{array}{l}\text { Labels 'feeling } \\
\text { worried, sad or } \\
\text { unhappy' dimen- } \\
\text { sion }\end{array}$ & Median value $^{a}$ & $\begin{array}{l}\text { Labels 'feeling } \\
\text { worried, sad or } \\
\text { unhappy' dimen- } \\
\text { sion }\end{array}$ & Median value ${ }^{b}$ & $\begin{array}{l}\text { Labels 'feeling } \\
\text { worried, sad or } \\
\text { unhappy' dimen- } \\
\text { sion }\end{array}$ & Median value $^{\mathrm{a}}$ & $\begin{array}{l}\text { Labels 'feeling } \\
\text { worried, sad or } \\
\text { unhappy' dimen- } \\
\text { sion }\end{array}$ & Median value $^{c}$ \\
\hline Gar nicht & 0 & No tengo & 0 & Inte & 0 & Not & 100 \\
\hline Nicht & 0.2 & Casi no tengo & 5 & Pyttelite & 1 & A little & 85 \\
\hline Kaum & 1.2 & Un poco & 15 & Lite grann & 1.9 & A bit & 70 \\
\hline Ein wenig & 2 & Algo & 20 & Lite & 2 & A lot & 35 \\
\hline Ein bisschen & 2 & Una leve & 35 & Bara lite & 2 & Really & 35 \\
\hline Leicht & 2 & Moderada & 50 & Något & 3 & Greatly & 15 \\
\hline Etwas & 3 & Bastante & 60 & Ganska & 5 & Terribly & 0 \\
\hline Große & 8 & Mucha & 70 & Mycket & 8 & - & - \\
\hline Besonders & 8 & Severa & 80 & Väldigt & 8 & - & - \\
\hline Sehr & 8.5 & Muchisimo & 85 & Jätte & 9 & - & - \\
\hline Ganz & 8.5 & Extrema & 90 & Extremt & 10 & - & - \\
\hline Total & 9 & Lo mas & 100 & - & - & - & - \\
\hline Extrem & 10 & - & - & - & - & - & - \\
\hline
\end{tabular}

aVAS from 0 to 10 was used. Anchor ' 0 ' was labelled as "not" and anchor ' 10 ' was labelled as 'extremely'

bVAS from 0 to 100 was used. Anchor ' 0 ' indicated the best status and anchor ' 100 ' indicated the worst status

'VAS from 0 to 100 was used. Anchor ' 0 ' was labelled as 'extremely' and anchor ' 100 ' was labelled as 'not'

statements was seen in Germany, where the label 'ein bisschen' (somewhat/a bit) was chosen for level 2 in the 'feeling worried, sad or unhappy' dimension. Based on the values given for the labels, 'leicht' (slightly) and 'ein wenig' (a few/a bit) were also possible options. However, participants mentioned that they would not use these words in everyday language in the context of being worried, sad or unhappy, so it was decided not to use them for this dimension.

\section{Phase 2}

\section{Cognitive interviews to test comprehension and feasibility of the extended $4 \mathrm{~L}$ and $5 \mathrm{~L}$ versions}

Sample characteristics for participants in phase 2 are shown in Table 6. Participants' comments indicated that they found both versions, EQ-5D-Y-4L and EQ-5D-Y-5L ${ }^{1}$, to be feasible to complete and easily understood “...it wasn't hard to complete and there were no difficult words" [boy, 12 years, Sweden]. In Germany and Sweden, no questions were raised about the labels for the severity levels or the general questionnaires, among either the younger or older participants.

In Spain, some of the labels which were chosen after the sorting and response scaling exercises caused problems for

\footnotetext{
${ }^{1}$ In the UK, only a $5 \mathrm{~L}$ version was developed and tested.
}

Table 6 Sample description for the participants of the cognitive interviews in phase 2 , by country

\begin{tabular}{|c|c|c|c|c|}
\hline \multirow{3}{*}{$n$} & Germany & Spain & Sweden & UK \\
\hline & 33 & 35 & 32 & 20 \\
\hline & $\%(n)$ & $\%(n)$ & $\%(n)$ & $\%(n)$ \\
\hline \multicolumn{5}{|l|}{ Gender } \\
\hline Boys & $48.5(16)$ & $51.4(18)$ & $68.8(22)$ & $40.0(8)$ \\
\hline Girls & $48.5(16)$ & $48.6(17)$ & $31.3(10)$ & $60.0(12)$ \\
\hline Missing & $3.0(1)$ & - & - & - \\
\hline \multicolumn{5}{|c|}{ Age-groups a(years) } \\
\hline $8-10$ & $33.3(11)$ & $42.9(15)$ & $65.6(21)$ & $50.0(10)$ \\
\hline $11-15$ & $66.6(22)$ & $57.1(20)$ & $34.4(11)$ & $50.0(10)$ \\
\hline \multicolumn{5}{|c|}{ Chronic/long-lasting illness } \\
\hline Yes & $51.5(17)$ & $54.3(19)$ & $46.9(15)$ & - \\
\hline No & $48.5(16)$ & $45.7(16)$ & $49.9(15)$ & - \\
\hline Don’t know & $0.0(0)$ & $0.0(0)$ & $6.3(2)$ & - \\
\hline EQ-VAS & Median & Median & Median & Mean \\
\hline $\begin{array}{l}\text { Participants } \\
\text { from general } \\
\text { population }\end{array}$ & 85.0 & 96.0 & 95.5 & 90.0 \\
\hline $\begin{array}{l}\text { Participants } \\
\text { with a } \\
\text { health con- } \\
\text { dition }\end{array}$ & $92.5^{*}$ & 89.0 & 85.0 & - \\
\hline
\end{tabular}

*Two missing values

${ }^{\text {a }}$ Dividing the age-groups like this is based on the split of age ranges in the field work in phase 1 and 2 
the participants. For example, in the 'mobility', 'looking after myself', and 'usual activities' dimensions, level 2 'un poco de problema' (a little bit of a problem) was changed to a more natural-sounding wording ('algún pequeño problema'). Some of the younger participants were also unsure how to interpret 'moderados' and 'moderadamente' (moderate) and, after discussion between the researchers and children it was decided to use 'bastante' (quite a lot) as the alternative which was closest and easiest to understand. Other changes included replacing 'muchísimos' (used in the 'mobility', 'looking after myself', 'doing usual activities' and 'pain and discomfort' dimensions) with the more childfriendly terms 'muchos' or 'mucho' (a lot) and replacing 'algo' (somewhat) with 'un poco' (a little) in the 'worried, sad or unhappy' dimension.

When directly asked for their opinion, the majority of the participants in Germany, Spain and Sweden, irrespective of their health status, preferred the EQ-5D-Y-5L (Germany: $88 \%$; Sweden: $66 \%$; Spain: $68 \%$ ) over the $4 \mathrm{~L}$ version. They felt it allowed them to rate their health in more detail. They commented that the $5 \mathrm{~L}$ version is more precise, and they liked the fact that it has a middle answer category. In Sweden, one respondent stated 'I thought the $5 L$ version was best because there were more options to choose from' [boy, 13 years, Sweden]. In Germany, one participant argued: '[...] you are not able to state your current health status [in the $4 L$ version] as precisely as in the $5 L$ version' [girl, 10 years, Germany]. Participants with health problems also noted that the EQ-5D-Y-5L provided more options for reporting severe health problems. Compared to the $5 \mathrm{~L}$ version, some participants had the feeling that answering the $4 \mathrm{~L}$ version was more difficult as there were fewer possibilities to choose from. However, two participants commented critically on the central response option in the $5 \mathrm{~L}$ as they thought it might be used by respondents who were unwilling to decide between answers. However, the central response category of the EQ5D-Y-3L has been used in previous studies without any evidence of this type of problem $[6,11,12]$.

In the UK, only the EQ-5D-Y-5L was tested and no children reported difficulties in completing it. There were no questions from the participants while answering the questionnaire and no missing data. However, the discussion of the words 'terrible'/'terribly' to describe level 5 in the dimensions 'having pain or discomfort' and 'feeling worried, sad or unhappy' with primary school children indicated the need for further attention as they were especially problematic. When language is embedded in a hierarchical structure then it could be assumed that the 'correct' understanding of a word is implied through its association with adjacent response categories. The label for severity level 5 defines the upper bound and has no scope for such a compensating mechanism. The UK team therefore considered the word 'extreme'/'extremely' as a replacement for 'terrible'/'terribly' since it was used in the other language versions. This was investigated in further interviews with a small number of children $(n=4)$ who confirmed this substitution.

The final language-specific $5 \mathrm{~L}$ versions can be seen in Table 7 , the $4 \mathrm{~L}$ versions that were included in the testing can be found in the online resource 1 (Table A1).

\section{Harmonization}

The comparison of the 5L versions occasionally showed divergent wordings for the labels. This was primarily due to (1) difficulties finding an exact translation for a term in English or (2) because a specific label was chosen based on participants' comments and therefore justified by the results of the field work. For example, the fourth level of the first three dimensions is 'a lot of' in English and-more or less-also in Swedish but 'große' (great) in German. The two labels are therefore not strictly equivalent but the alternative German wording of 'viele' (a lot of) was more frequently cited by participants in the German cognitive debriefing exercise as being unclear and an unusual wording. The term 'große' was therefore preferred. This also means that the youth version is consistent with the wording used in the German 5L adult version. The discussion of all labels and the slight discrepancies in the different languages showed that the labels were comparable, i.e., labels remained as developed by the national teams.

\section{Discussion}

In a process of identifying appropriate labels for an extended version of the EQ-5D-Y and testing the comprehensibility and feasibility, this study was successful in establishing a $5 \mathrm{~L}$ version of the EQ-5D-Y, the EQ-5D-Y-5L.

It is hoped that the development of this $5 \mathrm{~L}$ version will lead to an improvement over the EQ-5D-Y-3L in terms of its performance in general and sensitivity in particular. Compared to the EQ-5D-Y-3L, which defines 243 health states, the EQ-5D-Y-5L defines a broader spectrum of 3125 possible health states. However, the $5 \mathrm{~L}$ version will require further investigation in terms of testing its psychometric properties. The $5 \mathrm{~L}$ format maintains comparability with the corresponding adult version as do the adult and youth version of EQ-5D-3L. It is anticipated that this will allow continuous measurement of health status over a lifetime and also to permit comparison of results obtained using the two versions of the instrument [11]. This can be important when evaluating the impact of chronic disease which appears in childhood and lasts throughout adulthood [24].

As recommended in guidelines on the development of patient reported outcome (PRO) instruments, we made 


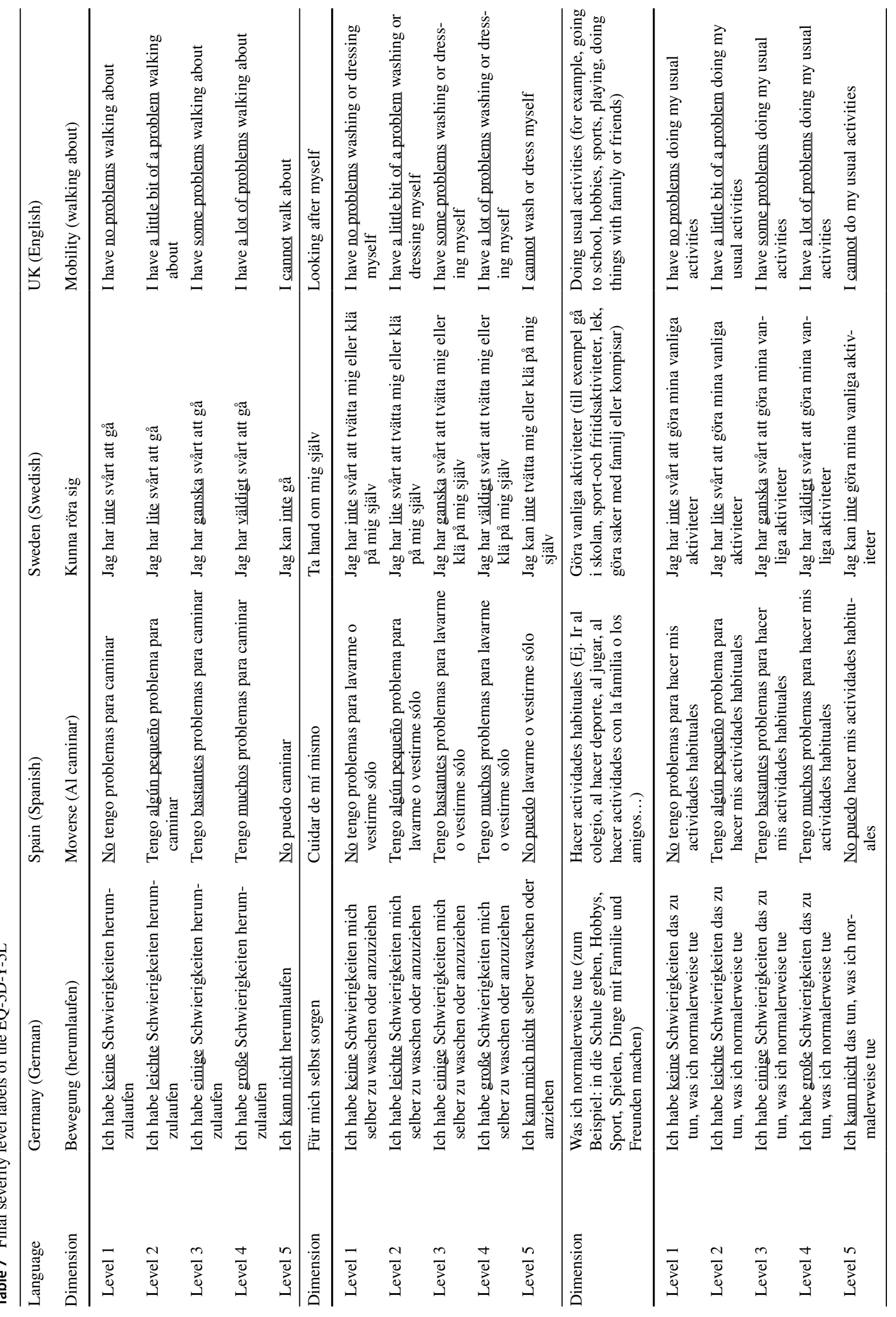




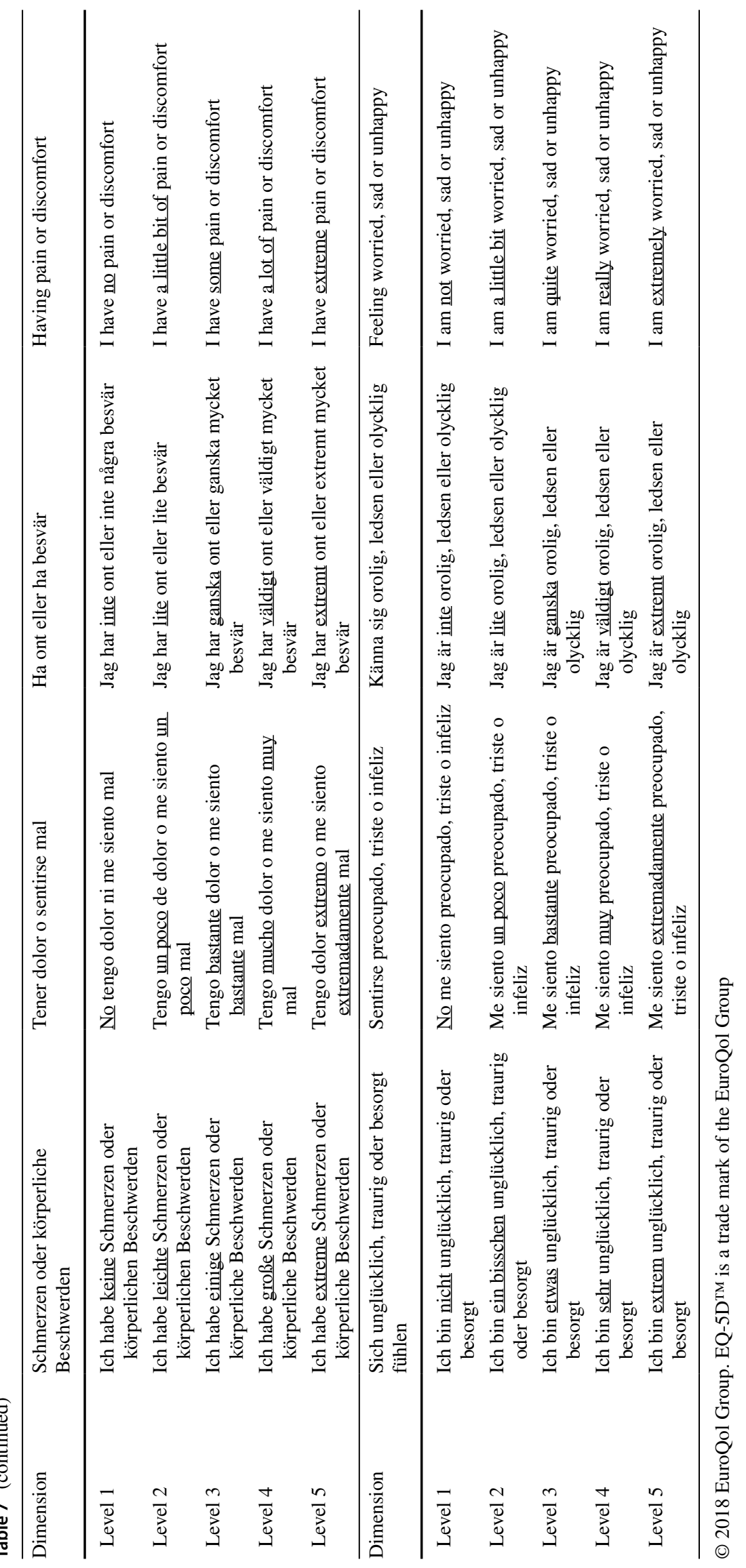


considerable efforts to take into account the views of the target group when developing the instrument [25-27]. Standardized procedures were co-designed across national research teams with children and adolescents being involved in the process at several stages to ensure development of an age appropriate instrument by using their preferred wording and everyday language wherever possible. In phase 1, participants reviewed preexisting labels as well as suggested possible new labels for use in the new version of the questionnaire based on understandable language and everyday speech of children. We found that participants of all ages were able to rate the severity of different labels using a sorting or response scaling task. This study is to the best of our knowledge the first to demonstrate the feasibility of using response scaling tasks in participants as young as eight. Participants contributed actively in phase 2 interviews and freely expressed their opinions about the different wording options offered. Overall, the ability of young persons to participate in studies using scientific methods should not be underestimated. The recruitment of children and adolescents as study participants is a challenge; in this study, it was especially difficult to recruit those with a health condition. Ideally, for the integration of the young peoples' perspective, it is necessary to involve them directly in research. Overall, the applied methods worked well in all countries, although the protocol adopted in the UK and in Spain deviated marginally from that employed elsewhere.

Comparing the EQ-5D-Y-5L and EQ-5D-Y-3L labels shows that the structure was not always changed in a similar way in all countries. Some of the labels from EQ-5D-Y-3L remained, while others were replaced. As it was found in the development of the adult EQ-5D-5L [28, 29], it would have been overly simplistic to simply insert an additional level between the original levels 1 and 2 and levels 2 and 3 . Hence, it was important to examine different labels for use in the extended versions.

This work on severity labels of the EQ-5D-Y descriptive system is also important in the context of future development of national value sets where the labels have to be valued as part of health state profiles, i.e., without the respondent seeing all severity labels of one dimension and their complete rank order as in the whole descriptive system.

A limitation of our study is that we used convenience samples in all countries and within both study phases; hence, the study population is not representative of the national population in each country. However, by including all age groups, boys and girls, and participants from different types of schools, we tried to ensure the inclusion of children and adolescents with a broad spread of characteristics.

The present study has produced a self-report version of the EQ-5D-Y-5L but future research will be needed to develop proxy-versions of the instrument. In the future, it will be important to conduct validation studies for the different language versions of EQ-5D-Y-5L in different groups of children and adolescents and especially among participants with different health conditions, to identify measurement properties of the instrument. The UK English version is assumed to be the source version for the translation of further language versions. It is also expected that research on valuation of the EQ-5D-Y-3L and EQ-5D-Y-5L will go on.

\section{Conclusion}

Children and adolescents in all participating countries contributed to the selection of candidate labels for an enhanced version of the EQ-5D-Y-3L and were able to rate the severity of different labels. They preferred the five-level version of EQ-5D-Y over the proposed four-level alternative. The new EQ-5D-Y-5L was comprehensible and feasible for children and adolescents in the age range 8-15 years and should provide a useful tool for those wishing to incorporate a short, simple, and easy to use measure of health status in their research. Before being used more extensively, further research to test the psychometric performance of the EQ$5 \mathrm{D}-\mathrm{Y}-5 \mathrm{~L}$ is required as well as an investigation of its feasibility for use in health state valuation exercises.

Acknowledgements Research was funded by a research grant (Reference Number: 2014160) awarded by the EuroQol Research Foundation.

\section{Compliance with ethical standards}

Conflict of interest All authors, except Miguel A. Perez-Sousa, are members of the EuroQol Group.

Ethical approval All procedures performed in studies involving human participants were in accordance with the ethical standard of the institutional and/or national research committee and with the 1964 Helsinki Declaration and its later amendments or comparable ethical standards. For this study, ethical approval was obtained from an ethics committee in each country.

Informed consent Informed consent was obtained from all individual participants (in the context of this study from the parents of the participating children and adolescents) included in the study.

Open Access This article is distributed under the terms of the Creative Commons Attribution 4.0 International License (http://creativeco mmons.org/licenses/by/4.0/), which permits unrestricted use, distribution, and reproduction in any medium, provided you give appropriate credit to the original author(s) and the source, provide a link to the Creative Commons license, and indicate if changes were made. 


\section{References}

1. Wille, N., Badia, X., Bonsel, G., Burström, K., Cavrini, G., Devlin, N., et al. (2010). Development of the EQ-5D-Y: A childfriendly version of the EQ-5D. Quality of Life Research, 19(6), 875-886.

2. Burström, K., Egmar, A.-C., Lugnér, A., Eriksson, M., \& Svartengren, M. (2011). A Swedish child-friendly pilot version of the EQ-5D instrument - the development process. European Journal of Public Health, 21(2), 171-177. https://doi.org/10.1093/eurpu $\mathrm{b} / \mathrm{ckq} 037$

3. Burström, K., Svartengren, M., \& Egmar, A.-C. (2011). Testing a Swedish child-friendly pilot version of the EQ-5D instrument-initial results. European Journal of Public Health, 21(2), 178-183. https://doi.org/10.1093/eurpub/ckq042.

4. Bergfors, S., Åström, M., Burström, K., \& Egmar, A.-C. (2015). Measuring health-related quality of life with the EQ-5D-Y instrument in children and adolescents with asthma. Acta Pediatrica, 104(2), 167-173.

5. Burström, K., Bartonek, Å, Broström, E. W., Sun, S., \& Egmar, A.-C. (2014). EQ-5D-Y as a health-related quality of life measure in children and adolescents with functional disability in Sweden: Testing feasibility and validity. Acta Pediatrica, 103(4), 426-435.

6. Eidt-Koch, D., Mittendorf, T., \& Greiner, W. (2009). Cross-sectional validity of the EQ-5D-Y as a generic health outcome instrument in children and adolescents with cystic fibrosis in Germany. BMC Pediatrics. https://doi.org/10.1186/1471-2431-9-55.

7. Herdman, M., Gudex, C., Lloyd, A., Janssen, M. F., Kind, P., Parkin, D., et al. (2011). Development and preliminary testing of the new five-level version of the EQ-5D (EQ-5D-5L). Quality of Life Research, 20(10), 1727-1736.

8. Janssen, M. F., Pickard, A. S., Golicki, D., Gudex, C., Niewada, M., Scalone, L., et al. (2013). Measurement properties of the EQ5D-5L compared to the EQ-5D-3L across eight patient groups: a multi-country study. Quality of Life Research: An International Journal of Quality of Life Aspects of Treatment, Care and Rehabilitation, 22(7), 1717-1727. https://doi.org/10.1007/s1113 6-012-0322-4.

9. Buchholz, I., Janssen, M. F., Kohlmann, T., \& Feng, Y.-S. (2018). A systematic review of studies comparing the measurement properties of the three-level and five-level versions of the EQ-5D. PharmacoEconomics, 36(6), 645-661. https://doi.org/10.1007/ s40273-018-0642-5.

10. Janssen, M. F., Bonsel, G. J., \& Luo, N. (2018). Is EQ-5D-5L better than EQ-5D-3L? A head-to-head comparison of descriptive systems and value sets from seven countries. PharmacoEconomics, 36(6), 675-697. https://doi.org/10.1007/s40273-018-0623-8.

11. Ravens-Sieberer, U., Wille, N., Badia, X., Bonsel, G., Burström, K., Cavrini, G., et al. (2010). Feasibilty, reliability and validity of the EQ-5D-Y: Results from a multinational study. Quality of Life Research, 19(6), 887-897.

12. Wu, X. Y., Ohinmaa, A., \& Veugelers, P. J. (2010). Sociodemographic and neighbourhood determinants of health-related quality of life among grade-five students in Canada. Quality of Life Research, 19(7), 969-976.

13. Varni, J. W. (2013). The PedsQL ${ }^{\mathrm{TM}}$ (measurement model for the pediatric quality of life inventory ${ }^{\mathrm{TM}}$. Boston, Mapi Research Trust.

14. Ravens-Sieberer, U., \& Bullinger, M. (1998). Assessing health related quality of life in chronically ill children with the German KINDL: First psychometric and content-analytical results. Quality of Life Research, 4(7), 399-407.

15. Heary, C.-M., \& Hennessy, E. (2002). The use of focus group interviews in pediatric health care research. Journal of Pediatric Psychology, 27(1), 47-57.
16. Detmar, S. B., Bruil, J., Ravens-Sieberer, U., Gosch, A., Bisegger, C., \& The European KIDSCREEN Group (2006). The use of focus groups in the development of the KIDSCREEN HRQL questionnaire. Quality of Life Research, 15(8), 1345-1353.

17. Schreier, M. (2012). Qualitative content analysis in practice. Thousand Oaks: SAGE Publications.

18. Keller, S. D., Ware, J. E., Gandek, B., Aaronson, N. K., Alonso, J., Apolone, G., et al. (1998). Testing the equivalence of translations of widely used response choise labels: Results from the IQOLA Project. Journal of Clinical Epidemiology, 51(11), 933-944.

19. Szabo, S. (1996). The World Health Organization Quality of Life (WHOQOL) Assessment Instrument. In B. Spilker (Ed.), Quality of life and pharmacoeconomics in clinical trials (2nd edn., pp. 355-362). Philadelphia: Lippincott-Raven.

20. Tomlinson, D., von Baeyer, C. L., Stinson, J. N., \& Sung, L. (2010). A systematic review of faces scales for the self-report of pain intensity in children. Pediatrics, 126(5), e1168-e1198. https ://doi.org/10.1542/peds.2010-1609.

21. Reynolds-Keefer, L., Johnson, R., \& Dickenson, T., \& McFadden, L. (2006). Validity issues in the use of pictorial likert scales. Studies in Learning, Evaluation Innovation and Development, 2009(3), 15-24.

22. University of Essex. Institute for Social and Economic Research NatCen Social Research Kantar Public. Understanding Society: Waves 1-7, 2009-2016: UK Data Service.

23. Collins, D. (2003). Pretesting survey instruments: An overview of cognitive methods. Quality of Life Research, 12, 229-238.

24. Eiser, C., \& Morse, R. (2001). Quality-of-life measures in chronic diseases of childhood. Health Technology Assess, 5(4), 1-157.

25. World Health Organization (WHO) - Division of Mental Health (1994). Measurement of quality of life in children. Report of a WHO/IACAPAP Working Party.

26. Patrick, D. L., Burke, L. B., Gwaltney, C. J., Leidy, N. K., Martin, M. L., Molsen, E., et al. (2011). Content validity-establishing and reporting the evidence in newly developed patient-reported outcomes (PRO) instruments for medical product evaluation: ISPOR PRO good research practices task force report: part 1eliciting concepts for a new PRO instrument. Value in Health: The Journal of the International Society for Pharmacoeconomics and Outcomes Research, 14(8), 967-977. https://doi.org/10.1016/j. jval.2011.06.014.

27. U.S. Department of Health and Human Services, Food and Drug Administration, Center for Drug Evaluation and Research, Center for Biologics Evaluation and Research, \& Center for Devices and Radiological Health (2009). Guidance for industry: PatientReported Outcome Measures: Use in Medical Product Development to Support Labeling Claims. Health and Quality of Life Outcomes, 4, 1-20

28. EuroQol Research Foundation (2015). EQ-5D-5L User Guide: Basic information on how to use the EQ-5D-5L instrument. Available from: https://euroqol.org/publications/user-guides

29. EuroQol Research Foundation (2018). EQ-5D-3L User Guide, Basic information on how to use the EQ-5D-3L instrument. Available from:https://euroqol.org/publications/user-guides

Publisher's Note Springer Nature remains neutral with regard to jurisdictional claims in published maps and institutional affiliations. 